\title{
EL TURISMO EN LA CIUDAD DE CÁCERES (1986-2010): UN CUARTO DE SIGLO EMBLEMÁTICO
}

\author{
Juan Ignacio Rengifo Gallego \\ Antonio-José Campesino Fernández \\ José Manuel Sánchez Martín \\ Universidad de Extremadura \\ irengifo@unex.es, acampesi@unex.es,jmsanche@unex.es
}

\section{RESUMEN}

Cáceres fue declarada por la UNESCO Ciudad del Patrimonio Mundial en el año 1986. A partir de ese momento se inicia una etapa clave en la que la ciudad experimenta una importante transformación a diferentes escalas, de entre las que destacamos: desarrollo urbanístico, gestión patrimonial y crecimiento del turismo. En este artículo analizamos la dinámica turística entre 1986 y 2010 por dos motivos fundamentales: la relación causal entre el despegue del turismo y la declaración de Cáceres como ciudad Patrimonio Mundial y la ausencia de artículos científicos que evalúen el proceso de desarrollo turístico en la ciudad de Cáceres durante este periodo.

Palabras lave: Cáceres, Patrimonio Mundial, desarrollo turístico, etapa clave, años 1986-2010.

\section{ABSTRACT}

Caceres was declared World Heritage Site in 1986 by UNESCO. Since then the city of Cáceres begins a period of intense transformation at three levels: urban development, cultural heritage management and tourism growth. In this paper we analyze the period between 1986 and 2010 for two main reasons: the causal link between the tourism development in Cáceres and the declaration of World Heritage Site and the absence of scientific papers that evaluate the tourism development process in this period.

Key words: Cáceres, World Heritage Site, tourism development, key period, 1986-2010.

Fecha de recepción: marzo 2013.

Fecha de aceptación: noviembre 2013. 


\section{INTRODUCCIÓN}

Con los antecedentes de la declaración de Cáceres como Conjunto Monumental el 21 de enero de 1949 y la posterior declaración de Tercer Conjunto Monumental de Europa en 1968, el 26 de noviembre de 1986 los ciudadanos de Cáceres recibieron la noticia de que su Ciudad Vieja había sido declarada Patrimonio Mundial de la UNESCO en la Asamblea General celebrada en París (UNESCO, 1986), bajo los Criterios (iii) y (iv):

«Las murallas de Cáceres aportan un testimonio excepcional de las fortificaciones realizadas por los Almohades en España. Comparada con la Torre de Espantaperros de Badajoz o la Torre del Oro de Sevilla, la Torre Mochada de Cáceres se integra en un conjunto de muros y torres representativo y largo tiempo conservado». Criterio (iii).

«Como varias ciudades de Italia, Cáceres ofrece un ejemplo eminente de villa dominada, de los siglos XIV al XVI, por poderosas facciones nobiliarias rivales, que dictaron la organización del espacio mediante la implantación de casas-fortaleza, casas-palacio y torres. Este ejemplo es considerado único por las características históricas específicas de esta villa de Extremadura, dónde se concitan, desde la Edad Media al Clasicismo, las influencias artísticas más diversas y más contradictorias (del Islam, gótico del norte, renacimiento italiano, de América, etc.)». Criterio (iv).

Con la inclusión de la «Ciudad Vieja de Cáceres», como Bien 384 de la Lista del Patrimonio Mundial, la UNESCO reconoce que la Ciudad Vieja de Cáceres es un Conjunto Monumental de 7,8 hectáreas, delimitado por un perímetro amurallado de 1.174,7 metros, que contiene una variedad tipológica-constructiva de casas-fortaleza y casas-palacio góticorenacentistas, pertenecientes a la nobleza, así como arquitecturas religiosas de iglesias, ermitas y conventos de gran valor. Aquella declaración supuso, sin duda, un punto de inflexión en la transformación de la ciudad con repercusiones directas en la dinámica urbanística y patrimonial, tal y como reseñamos cronológicamente a continuación:

- Urbanismo. Poco antes de la declaración de Patrimonio Mundial, y por Acuerdo Pleno Municipal de 30 de diciembre de 1985, se encarga la revisión del Plan General de Ordenación Urbana de 1976 (redactado por Francisco Fernández Longoria y Genaro Alas -AUR-), al arquitecto cacereño Guillermo Alcón Olivera y a su equipo local (Alcón et al, 1991), supervisado por el arquitecto municipal Miguel Madera Donoso, cuyo Avance de Ordenación del núcleo y del mayor término municipal de España (176.849 Has) se presentó a exposición pública durante los meses de abril y mayo de 1991, y por cambios normativos estatales no obtuvo aprobación hasta el 28 de octubre de 1998. Desde aquel momento, y en las dos décadas siguientes, el urbanismo cacereño discurrió por unos derroteros que apuntamos de forma sintética.

Cáceres era una ciudad con evidentes síntomas de envejecimiento. Disponía de un parque habitacional de 28.000 viviendas, afectado por la contradicción entre elevada 
demanda insatisfecha y despilfarro de más de 3.000 viviendas vacías o cerradas en el Centro Histórico (Guerrero, 1991), con un problema claro de integración en la estructura general de la ciudad. Las determinaciones del planeamiento produjeron una gran oferta de suelo residencial, mediante los Programas de Actuación Urbanística (P.A.U.). La implantación de instalaciones de actividades secundarias y terciarias comienza a colmatar el suelo industrial calificado, al tiempo que se consolidan las actividades clandestinas en coexistencia contradictoria con núcleos residenciales. Se aprecia una irregular distribución de los equipamientos (docentes, sanitarios, institucionales, asistenciales, deportivos y de ocio), que plantean déficits locales (guarderías) e infrautilización (instalaciones deportivas de la Diputación en Aldea Moret), así como una deficitaria dotación de espacios libres y verde público. Por efecto de las prácticas urbanísticas de los años ochenta, el modelo urbano resultante es difuso, de crecimiento «a saltos» sobre una periferia dispersa y discontinua con intercalación de grandes vacíos intersticiales, sin tratamiento de bordes urbanos y con una débil integración urbana, en gran parte motivada por el desfase en la tramitación del PGOU de 1976 y por la utopía de sus proyecciones demográficas.

- Ordenación patrimonial. En paralelo al discurso urbanístico, la ordenación patrimonial se gestionará bajo diferentes parámetros. En primer lugar, y por efecto de la implantación en 1973 del distrito cacereño de la Universidad de Extremadura (UEX), la nueva función universitaria iba a suponer toda una revolución cultural que cambiaría el perfil funcional de Cáceres, hasta el extremo de ser reconocida dos décadas después como Capital Cultural de Extremadura (1992), con beneficioso refuerzo de la multifuncionalidad residencial, institucional, administrativa, sanitaria, comercial y de ocio lúdico (eclosión de la célebre movida cacereña). La inclusión de la Ciudad Vieja de Cáceres en el Patrimonio Mundial de la UNESCO (1986) reforzó, asimismo, la imagen de marca patrimonial de una pequeña capital de provincia, al posicionarla en el techo máximo de la proyección internacional: un Casco Antiguo, conceptuado como el conjunto más homogéneo de arquitectura civil gótico-renacentista, en el que prima el valor del todo sobre los elementos singulares. En segundo lugar, y por mandato del art. 20.1. de la Ley 16/1985, de 25 de junio, del Patrimonio Histórico Español (LPHE), el Ayuntamiento de Cáceres encargó la redacción del Plan Especial de Protección y Revitalización del Patrimonio Arquitectónico de la Ciudad de Cáceres -PEPRPACC-, al arquitecto Santiago Rodríguez Gimeno (DELTA SUR, S. L., 1987), con aprobación provisional en 1987 y definitiva el 8 de marzo de 1990. Su ámbito de intervención abarca el perímetro del Conjunto Histórico (99,3 Ha, 1.756 inmuebles, 3.180 viviendas y 7.000 habitantes) y el documento aún se mantiene sin revisar, incomprensiblemente, tras 23 años de vigencia. El PEPRPACC no entendió que el Casco Antiguo intramuros era el marco privilegiado para mantener e incrementar el Campus Interno de la UEX cacereña, y propuso el dislate urbanístico-patrimonial-universitario de ubicación en un campus externo a la americana (dejando el Rectorado y los Servicios Centrales en el recinto intramuros). Por efecto de la descoordinación urbanística-patrimonial-universitaria, a partir de 1995 el Casco Antiguo y el Centro Histórico de Cáceres perdieron la oportunidad irrepetible de mantener las acti- 
vidades universitarias en las arquitecturas patrimoniales de un campus interno de lujo, concentrando a los 10.000 alumnos, que tanto dinamismo habían generado en la ciudad histórica hasta entonces, lo que desencadenaría un proceso de regresión del casco intramuros convertido en un museo de piedra al aire libre, monumental, pero sin sangre, desvitalizado.

Lógicas consecuencias iban a ser la despoblación y el envejecimiento, contrarrestadas entre 1990 y 2006 con la incorporación de 2.500 nuevos residentes, pasando el censo poblacional de 7.000 por 9.503 habitantes, con un incremento del $36 \%(2,4 \%$ anual), según datos de la Oficina Municipal del Área de Rehabilitación Integrada, bajo la supervisión de José Luis Sánchez de la Calle. Para enfrentar tales problemas demográficos estructurales se hubieran requerido políticas decididas de rehabilitación residencial y de renovación urbana para la promoción de nueva vivienda pública de protección oficial y libre privada. Ello no ha sido posible por el deterioro selectivo del parque inmobiliario, ya que mientras las arquitecturas monumentales han sido objeto de rehabilitación y refuncionalización (Campesino, 2004) para nuevos usos institucionales, administrativos, culturales, universitarios y hoteleros con cuantiosas inversiones públicas y privadas, las modestas arquitecturas populares del llano no han corrido idéntica suerte, por la falta de recursos de sus propietarios y la escasez de ayudas públicas a la rehabilitación residencial, agudizándose en determinados sectores el carácter de infravivienda.

Los cambios urbanísticos y de ordenación patrimonial de la ciudad de Cáceres se vieron acompañados, en la etapa 1986-2010, por otros procesos de transformación que han hecho de Cáceres una ciudad diferente, cuyos principales rasgos esbozamos a continuación:

- Cambios demográficos. El padrón de habitantes del año 2010 situó la población en 94.179 habitantes. Estos dígitos muestran un notable crecimiento de su población absoluta en el periodo objeto de estudio, algo que, por otra parte, no es extraordinario en términos comparativos con los núcleos de población de más de 20.000 habitantes de Extremadura durante ese mismo periodo. No obstante, durante el periodo 19862010, de las siete localidades extremeñas que superaron la barrera de los 20.000 habitantes (Almendralejo, Badajoz, Cáceres, Don Benito, Mérida, Plasencia y Villanueva de la Serena), fue Cáceres la que registró un incremento porcentual superior, con un $36,11 \%$, al pasar de los 69.193 de 1986 (población de hecho) a los 94.179 habitantes de 2011 (rectificación padronal). Por el contrario, esta dinámica no es observable en la mayor parte de los 221 municipios de la provincia de Cáceres, inmersos en un declive poblacional que los arrastra con deriva implacable hacia el envejecimiento y la consunción demográfica. Asimismo, el dinamismo de la ciudad de Cáceres contrasta con el que se aprecia a escala regional o provincial. Sirva como botón de muestra, para verificar esta aseveración, el periodo comprendido entre 1991 y 2010, etapa en la que, mientras se coteja un crecimiento del $26 \%$ en la ciudad, a nivel regional el incremento no pasa de un tenue $3,9 \%$.

- Terciarización. Ante la ausencia de un tejido empresarial vinculado al sector secundario, la ciudad ha alcanzado un estadio de sociedad postindustrial en el que el $81,8 \%$ de los trabajadores de Cáceres llevan a cabo una actividad relacionada con el sec- 
tor servicios, cuyas empresas representan el 77,9\% del total de las existentes (Caja España, 2011). Algunos de los sectores que han ganado mayor protagonismo en este ámbito han sido el educativo (Universidad), sanitario (Hospitales), judicial (Audiencia Territorial), comercio (grandes superficies) e industria del ocio. Estos porcentajes contrastan con los registrados en las poblaciones de menor rango demográfico, donde el peso del sector primario es considerablemente mayor, en detrimento del resto de sectores con escasas oportunidades de crecimiento.

- Accesibilidad. La buena renta de situación se deriva del posicionamiento geográfico privilegiado en el histórico eje Norte-Sur que conforma la Vía de la Plata, convertida en autovía en sus aproximadamente 800 kilómetros (A-66), con excepción del trayecto Zamora-Benavente. A ello se suma la reciente conexión Cáceres-Trujillo por la autovía (A-58) con la (A-5) Madrid-Badajoz-Lisboa, vía radial de alta velocidad y principal eje articulador de la península ibérica. Con ello, la accesibilidad terrestre por carretera es buena, a la espera de que se complete, con permiso de la crisis, la conexión por ferrocarril en su modalidad de Alta Velocidad. La conexión por vía aérea depende del aeropuerto (militar de uso civil compartido) de Talavera la Real-Badajoz (distante a $100 \mathrm{~km}$ ), cuya reducida oferta de enlaces se ciñe a vuelos domésticos y, esporádicamente, internacionales durante la época estival. Conexiones sometidas, con frecuencia, a una permanente volatilidad: cambios de compañías, cancelaciones de rutas y horarios cambiantes que dificultan que este medio de transporte goce de la confianza continuada de los consumidores. Por ello, la intermodalidad sigue siendo la principal asignatura pendiente de la ciudad.

- La cultura y el patrimonio como ejes de desarrollo. La existencia de un rico patrimonio histórico, las políticas de valorización relacionadas con estos bienes, la programación de actividades culturales, las acciones promocionales y la paulatina integración en el mercado turístico de la ciudad de Cáceres han favorecido la creciente llegada de flujos turísticos, con el subsiguiente impulso de la industria del turismo (ICOMOS, 1999). La suma de estos factores ha contribuido a la puesta en marcha de iniciativas que han repercutido en la dotación de equipamientos generales y específicos pensados para la acogida de viajeros y, por ende, al fortalecimiento del sector terciario con las consabidas repercusiones a nivel del empleo. Durante el año 2011, el personal ocupado en la ciudad de Cáceres en el sector hotelero (donde están representados las cinco categorías de hoteles, dos de hostales y pensiones), osciló entre las 280 personas del mes de enero y las 421 del mes de agosto (INE, 2011). A esta cifra habría que incorporar los empleos generados directamente por el turismo en bares, restaurantes, oficinas de información, tiendas especializadas y centros de visitantes, mucho más numerosos.

Con estas referencias, en las que atribuimos al turismo una clara responsabilidad en el proceso de cambio experimentado por la ciudad, abordamos en este artículo la evaluación del proceso turístico vivido por Cáceres en los últimos cinco lustros, tomando como punto de partida el año en que se produjo la declaración de Cáceres como Patrimonio Mundial. Para ello, el trabajo se ha estructurado en tres grandes epígrafes: en el primero de ellos se analizan con detalle los pilares sobre los que se sustenta el turismo cacereño, para posteriormente 
examinar el desarrollo de la actividad turística (alojamientos y equipamientos complementarios) y estudiar el comportamiento de los flujos. La justificación para realizar este trabajo de investigación, con este objetivo y estos parámetros temporales, obedece a dos motivos fundamentales: la relación causal entre el despegue del turismo y la declaración de Cáceres como ciudad Patrimonio Mundial (ICOMOS, 1977) y la ausencia de artículos científicos que evalúen el proceso de desarrollo del turismo en la ciudad de Cáceres en un periodo clave para su consolidación.

Hasta el momento, la ciudad de Cáceres ha sido objeto de estudios monográficos relacionados con su patrimonio, desde diferentes enfoques: urbanismo histórico (Lozano, 1980), geografía urbana (Campesino, 1982) y urbanismo patrimonial (Pizarro, 2002), siendo muy escasas las aportaciones monográficas referidas al desarrollo turístico de Cáceres que, además, tienen una perspectiva temática y temporal más reducida que la propuesta (Campesino, 1999 y 2004) y (Rengifo, 2011).

\section{LOS PILARES PATRIMONIALES DEL TURISMO CACEREÑO}

Cáceres es una ciudad histórica bimilenaria, resultado del crisol de civilizaciones, superpuestas y yuxtapuestas sobre el molde genético fundacional. El temprano proceso de humanización del territorio cacereño (30.000 años a.C.) aparece documentado en 1951 por los restos arqueológicos del Paleolítico Superior de la Cueva de Maltravieso, bajo la cubeta cárstica del Calerizo, al SO de la ciudad. No obstante, la fundación de la ciudad se adscribe a los veteranos que abandonan el campamento militar de Castra Caecilia Cáceres el Viejo, situado a $3 \mathrm{~km}$ al NE de la ciudad actual, en el año 35-36 a.C. Eligen emplazar la colonia «Norba Caesarina» sobre un cerro $(459 \mathrm{~m})$ de topografía compleja con plataformas a distintos niveles (San Mateo -459 m- y Santa María -441-), que emerge sobre la penillanura externa (400 m), entre las fosas tectónicas de la Ribera del Marco y de Aguas Vivas, rodeado por los contrafuertes de la Sierrilla (523 m) al NO, y de la Sierra de la Mosca (606 m) al SE, que culmina en el Cerro del Portanchito (644 m).

En el siglo III, la amenaza de las invasiones bárbaras obligará a fortificar el emplazamiento con una muralla perimetral, dotada de cuatro puertas de acceso y un postigo, que fijará los bordes morfológicos del binomio dentro-fuera y protegerá la villa intramuros hasta el presente, reconocible aún por los sillares graníticos (altura de 30 a $60 \mathrm{~cm}$ ) de cimentación, colocados a soga y tizón sin argamasa, en el Arco de la Puerta del Río y en las cimentaciones de torres y paramentos de muralla.

Del siglo V al XII desaparecen las noticias de la villa, hasta que el geógrafo Al-Idrisi (1100-1165) la describe en sus crónicas, como una plaza fuerte de frontera con el territorio cristiano. A partir de 1174, los almohades reconstruirán el perímetro fortificado, reutilizando como cimentación los sólidos sillares romanos, cerrando los paramentos con tapial y construyendo de nuevo cuño una línea avanzada de torres albarranas para la defensa y un camino de ronda superior. Leopoldo Torres Balbás estima que la cerca almohade debió disponer de barbacana o muralla avanzada con un perímetro de 1.145 metros y superficie intramuros de $7,74 \mathrm{Ha}$, que contendría un parque de 421 casas y unos 2.500 moradores (Torres y Terrasse, s.f.). Importa señalar que esta muralla almohade será definitiva para la declaración de la Ciudad Vieja de Cáceres, como Patrimonio Mundial de la UNESCO. 


\section{II.1. La villa medieval cristiana}

A partir del Fuero y de la Carta de Población (1229) de Alfonso IX, Cáceres será villa de realengo, franca y libre, con un alfoz de 200.000 Ha para favorecer la llegada de repobladores norteños a una tierra yerma, extrema e insegura. Los pobladores levantan sus casas dentro del espacio intramuros y entre sus obligaciones se encuentra la de conservar y reparar la muralla, que define el derecho de vecindad frente a los forasteros exógenos. La vida urbana intramuros se organiza en torno a las dos parroquias de Santa María (XIII) y su plaza y San Mateo (XIV), sobre la mezquita, con su plaza, alineadas en el eje director SSO-NNE y dotadas de sus colaciones respectivas. A partir del siglo XIV y durante el siglo XV la oligarquía nobiliaria se apropia del espacio intramuros, mediante la agregación parcelaria de solares, para la construcción de una primera tipología de casas-fortaleza medievales con potentes torreones, sin otra función defensiva que la de competir entre linajes por el control de la villa y del territorio. Se produjo una transición notable del minifundismo parcelario de arquitecturas domésticas a la génesis de grandes edificios.

Desde que en 1303 el monarca Fernando IV concedió al Concejo las rondas exteriores de la muralla por juro de heredad para habilitar construcciones, se produce el sventramento de la población pechera en torno a las parroquias extramuros de Santiago (XIII) y de San Juan (XIV), con sus colaciones respectivas, que generarán los primeros cinturones edificados con un modelo de plano anular articulado por el ejido o espacio abierto de feria y mercado, ante la fachada occidental de la muralla.

Se cumple también en Cáceres el axioma defendido por Eduardo Martínez de Pisón en Segovia: «La iglesia está en el centro de todo, del pueblo, de la vida y de la muerte: bautiza, centra, dirige y entierra. Inicia el poblamiento y lo ordena; todas las actividades públicas se sitúan en ella, polarizando la organización de la comunidad... (sic); donde se reunían los habitantes para tratar casi todos sus temas colectivos de esta vida y de la otra, es magnífica muestra del lugar central ocupado por la iglesia desde los orígenes de la ciudad» (Martínez de Pisón, 1976).

A finales del siglo XV, Cáceres es ya una villa con antagonismos y dualidades topográficas, urbanísticas, arquitectónicas, sociales y económicas en la ocupación del suelo. Asistimos en Cáceres al temprano y definitivo proceso de superación de los límites murados, sin necesidad de proceder al derribo de la muralla, de modo que ello permite la distinción nítida entre: Villa Alta (residencial y religiosa) o Casco Antiguo intramuros y Villa del Llano o Centro Histórico extramuros, cerrada, hermética y privatizada, frente a la villa abierta y dinámica; arquitecturas singulares nobiliarias, concentradas en el Casco, y populares pecheras de los barrios populares; reparto equitativo de las funciones religiosas con dos parroquias internas y otras dos externas; correspondencia de espacios libres (correderas) ante las respectivas iglesias exentas, y dualidad funcional entre las actividades primarias y artesanales de la Ribera del Marco al mediodía y las terciarias de feria y mercado sobre el ejido, todavía abierto, del flanco occidental.

\section{II.2.La eclosión de la villa moderna, renacentista, barroca e ilustrada}

Cáceres renacentista se fragua en el tránsito de los siglos XV al XVI y eclosiona hasta alcanzar su máximo apogeo a finales de este periodo. La villa intramuros prosigue su proceso de construcción de arquitecturas singulares, a partir de los beneficios de la tierra y de las 
remesas del oro americano, con una nueva tipología señorial renacentista de casas-palacio de gran superficie, que ocupan manzanas enteras, superando con creces el millar de $\mathrm{m}^{2}$.

Esta aportación permite diferenciar la nítida transición conceptual y tipológica entre las casas-fortaleza medievales y las casas-palacio renacentistas, todas con patio interior de una planta o dos, de arquerías simples o superpuestas, organizadas de dentro a fuera (reminiscencia conceptual islámica). Sin ser piezas de singular arquitectura, confieren unidad constructiva a la villa alta, conformando el conjunto más homogéneo de arquitectura civil gótica-renacentista peninsular, con una treintena de torres palaciegas (desmochadas en su mayoría por Isabel la Católica) y defensivas, que junto a las espadañas de las iglesias intramuros y extramuros perfilan la silueta monumental de Cáceres, como hitos urbanos y símbolos ostentosos de los poderes terrenales y celestiales.

Esta aportación al urbanismo mediterráneo fue tenida en cuenta por la UNESCO para la declaración de Patrimonio Mundial, al concitarse en la Ciudad Vieja de Cáceres las influencias artísticas más diversas y contradictorias: desde la Edad Media al Clasicismo, (del Islam, gótico del norte, renacimiento italiano, de América, etc.).

A la villa alta de muros adentro, hermética, señorial, eclesiástica y de manos muertas se opone ahora la villa del llano, abierta, mercantil y pechera. El ejido abierto se urbaniza y se convierte en Plaza Pública rectangular y desnivelada de $\mathrm{S}$ a N, mediante el cierre de los tres flancos a partir del lienzo de la muralla con edificaciones de dos alturas sobre soportales (1577). La Plaza se convierte en centro multifuncional, por cuanto, al desplazar el mercado ganadero a la plazuela de San Juan, el espacio público adquiere un valor simbólico (desfiles religiosos, corridas de toros, festejos, con el derecho a las «alegrías» de las ventanas), administrativo por desplazamiento de las Casas Consistoriales al Foro de los Balbos (1554) y focalizador de la red caminera (Sevilla-Salamanca-Madrid y Portugal).

\section{II.3. La ciudad burguesa (1830-1930)}

La población de Cáceres duplica sus efectivos humanos a lo largo del siglo XIX, pasando de 7.340 habitantes en 1829 a 15.442 en 1897, para cuadruplicarlos en el siglo de análisis y alcanzar los 25.869 en 1930. Hitos explicativos de este dinamismo son: la consecución de la capitalidad provincial (1833), que reforzará su protagonismo urbano sobre el territorio con la concentración de servicios terciarios y la atracción inmigratoria; el descubrimiento de los fosfatos de Aldea Moret (1866), a $3 \mathrm{~km}$ al Sur de la ciudad, cuya explotación minera se prolongará durante un siglo, y la paralela llegada del ferrocarril MCP (1881), que rompe el secular aislamiento de Cáceres. En el plano de Coello se mantiene la dualidad de «Villa Antigua de Adentro» y «Villa Moderna», que se estructuran y ordenan en cuatro cuarteles (Santiago, San Juan, Santa María y San Mateo), zonificados sobre la primitiva jurisdicción eclesiástica, que adscribe los barrios centrales y periféricos a los nuevos criterios censales (distritos y manzanas).

\section{II.4. Conjunto Histórico y políticas de protección (1931-1990)}

Pese a las bienvenidas normativas de protección, en la media centuria anterior a la gestión democrática del patrimonio (1985), las políticas de conservación del llamado «Estilo Bellas 
Artes», favorecieron la restauración iluminista, la deslocalización de elementos patrimoniales cacereños por José Manuel González Valcárcel (arquitecto-conservador), la eclosión de pastiches y el folclorismo pintoresco patriótico-elitista de considerar únicamente dignas de protección las arquitecturas de pedigrí del cogollo intramuros, con total despreocupación de los problemas socio-económicos del Conjunto Histórico.

Las graves dolencias de tales conjuntos, afectados por despoblación, especulación y terciarización, reclaman nuevos planteamientos conceptuales y metodológicos para enfrentar las nuevas estrategias nacidas de la crisis urbana (1975-1985), dispuestas a capitalizar el valor de centralidad de los patrimonios urbanos en reserva de rentabilidad expectante.

El Conjunto Histórico de Cáceres (Casco Antiguo y Centro Histórico) no fue una excepción, porque en las preocupaciones morfológicas de conservacionismo museístico del recinto monumental no tuvo cabida la solución de los procesos de deterioro social, funcional y ambiental del resto del centro y de sus bordes de respeto, alterados por las agresiones renovadoras de los sesenta y setenta.

\section{II.5. La Ciudad Vieja de Cáceres, Patrimonio Mundial de la UNESCO}

El Consejo de Europa declaró a Cáceres Tercer Conjunto Monumental de Europa, tras Praga y Tallín, en 1968. El 26 de noviembre de 1986, la Ciudad Vieja de Cáceres fue declarada Bien del Patrimonio Mundial de la UNESCO. La evaluación de la autenticidad/integridad del Bien por los miembros de ICOMOS en el momento de la inscripción consideró que las murallas de Cáceres aportan un testimonio excepcional de las fortificaciones realizadas por los Almohades en España; que el Cáceres de los siglos XIV al XVI ofrece un ejemplo eminente de villa señorial con implantación de casas-fortaleza, casas-palacio y torres, y que las características históricas de la villa de Cáceres la convierten en ejemplo único de yuxtaposición de las influencias y estilos más diversos y contradictorios entre la Edad Media y el Clasicismo.

La inscripción de Cáceres en la Lista del Patrimonio Mundial se produjo con anterioridad a la aprobación definitiva del Plan Especial de Protección del Patrimonio Arquitectónico, razón por la cual la Ciudad Vieja y el Conjunto Histórico carecían en aquel momento de figuras de ordenación-protección y de instrumentos de gestión integrada de políticas patrimoniales y urbanísticas.

El Art 20.1 de la Ley 16/1985, de 25 de junio del Patrimonio Histórico Español obliga a todo Conjunto Histórico declarado a redactar un Plan Especial de Protección del área afectada. En consecuencia, en 1986 el Ayuntamiento de Cáceres adjudica la redacción del Plan Especial de Protección y Revitalización del Patrimonio Arquitectónico de la Ciudad de Cáceres (PEPRPACC), al equipo Delta Sur, S. L., dirigido por el arquitecto Santiago Rodríguez Gimeno, que lo ultima en 1987, aunque su aprobación definitiva se prolonga hasta el 8 de marzo de 1990.

Para los análisis, diagnósticos y propuestas, el PEPRPACC divide el Conjunto Histórico de Cáceres en cinco áreas homogéneas: Área 1 (Recinto Monumental Amurallado), Área 2 (Santiago), Área 3 (Margallo), Área 4 (San Juan) y Área 5 (Santa Clara o sector Sureste).

Debido a la antigüedad de las construcciones, gran parte de ellas presentaban en 1990 deficiencias de diversa índole, por fatiga de los materiales, abandono e inadecuación funcio- 
nal a las demandas actuales de habitabilidad. El estado de infravivienda se reflejaba en las patologías constructivas (cubiertas y estructuras deterioradas por grietas, flechas, desplomes, humedades, solerías rotas, carpinterías y cerrajerías inservibles...), en las infraestructuras básicas medievales (pozos ciegos, atarjeas, cañerías y desagües en mal estado, con resultados ambientales deplorables), en la carencia de iluminación y ventilación directa por distribuciones caóticas (cuartos de baños en patios, dormitorios como paso obligado a otras dependencias, alcobas ciegas), fruto de la sub-parcelación interna histórica y del elevado hacinamiento por demanda insatisfecha de vivienda obrera.

En todas las épocas las ciudades han sido identificadas por sus monumentos arquitectónicos, obras de arte que siglo a siglo han ido configurando estilos y tipologías, fácilmente reconocibles, y que se han incorporado al patrimonio artístico y cultural. El rango patrimonial de los destinos urbanos turístico-culturales radica en la imagen que los conjuntos históricos y las arquitecturas catalogadas ofrecen a los potenciales visitantes, ya que la primera percepción de éstos reside en la sucesión de elementos arquitectónicos singulares. Dado que los equipamientos culturales son instrumentos de vertebración urbana y de integración social, conviene pasar revista al proceso de rehabilitación del viejo patrimonio cacereño para dar cobijo a nuevas funciones administrativas, culturales, universitarias y turísticas.

En 1987, el Ayuntamiento de Cáceres creó la Oficina Municipal de Rehabilitación, que en 1994 pasó a tener ámbito comarcal. Su objetivo respondió al contenido del Decreto 726/1993, sobre medidas de financiación para actuaciones urbanísticas-arquitectónicas a realizar en el Conjunto Histórico.

De 1981 a 1990, la política de rehabilitación de edificios rehabilitados para usos públicos presentaba como estandartes el Monasterio de San Francisco, que albergaba el Complejo Cultural San Francisco, con la Institución Cultural «El Brocense» de la Diputación Provincial de Cáceres; el Palacio de los Rivera para sede del Rectorado de la Universidad de Extremadura; las Delegaciones de la Junta de Extremadura en la Plaza de Santa María; los Museos Municipal y Provincial y el proceso de reconversión del Palacio de Moctezuma para Archivo Histórico Provincial. En total, las rehabilitaciones llevadas a cabo tuvieron las siguientes finalidades: equipamientos culturales (10), equipamientos universitarios (4), equipamientos turístico-hoteleros (4) y equipamientos institucionales (3).

\section{II.6. Síntesis}

En suma, este espectacular patrimonio ha ido acumulando reconocimientos proclives a estimular unos flujos turísticos que en 1986 eran muy débiles. A los ya referidos de Patrimonio Mundial y Tercer Conjunto Monumental de Europa se unen, entre otros, el Pomme d'Òr al Mérito Turístico, otorgado por la Federación Internacional de Periodistas y Escritores de Turismo (1996), la declaración de su Semana Santa como Fiesta de Interés Turístico Internacional (2011) y la sucesiva incorporación de diferentes Bienes al listado de los BIC (Bienes de Interés Cultural): Monumentos (15), Zona Arqueológica (1), Conjunto Histórico (1) y Lugar de Interés Etnológico (1). Relación a la que cabría incorporar la Vía de la Plata en su calidad de Bien de Interés Cultural con la categoría de Sitio Histórico (Tabla 1). En total, 19 BIC que vienen a representar casi un 15\% de todos los existentes en la provincia de Cáceres, 7 de los cuales han sido declarados en los últimos 25 años. 
Asimismo, cabe reseñar la incorporación de Cáceres a redes de ciudades con intereses comunes para la configuración de productos turísticos específicos: Red de Juderías o Red de Ciudades Patrimonio de la Humanidad.

Tabla 1

BIENES DE INTERÉS CULTURAL DE CÁCERES. AÑO 2012

\begin{tabular}{|l|c|c|}
\hline BIENES DE INTERÉS CULTURAL & CATEGORÍA & FECHA \\
\hline Muralla almohade & Monumento & D. 27/08/1930 \\
\hline Ruinas romanas «Cáceres el Viejo» & Monumento & D. 04/06/1931 \\
\hline Casa de las Veletas & Monumento & D. 04/06/1931 \\
\hline Palacio de los Golfines de Abajo & Monumento & D. 04/06/1931 \\
\hline Casa Mudéjar & Monumento & D. 04/06/1931 \\
\hline Iglesia Concatedral de Santa María & Monumento & D. 04/06/1931 \\
\hline $\begin{array}{l}\text { Conjunto Histórico (Palacio de Abrantes, Casa de los Trucos, } \\
\text { Casa Plaza de la Concepción, Casa de la Roca, Colegio Viejo } \\
\text { de San Pedro, Iglesia de Santiago, Convento de San Francisco, } \\
\text { Ermita del Espíritu Santo, Santuario de Nuestra Señora de la } \\
\text { Montaña }\end{array}$ & $\begin{array}{l}\text { Conjunto } \\
\text { Histórico }\end{array}$ & D. 21/01/1949 \\
\hline Museo de Bellas Artes & Monumento & D. 09/03/1962 \\
\hline Cueva de Maltravieso & $\begin{array}{c}\text { Zona } \\
\text { Arqueológica }\end{array}$ & D. 25/05/1963 \\
\hline Palacio de los Golfines de Arriba & Monumento & D. 30/01/1978 \\
\hline Archivo Histórico Provincial de Cáceres & Monumento & D. 29/06/1985 \\
\hline Oratorio-Enfermería de San Pedro de Alcántara & Monumento & D. 04/12/1990 \\
\hline Palacio del Marqués de Camarena & Monumento & D. 09/07/1992 \\
\hline Plaza de Toros & Monumento & D. 17/03/1992 \\
\hline Inmueble 13 de la Avenida de España & $\begin{array}{l}\text { Monumento } \\
\text { Monumento }\end{array}$ & $\begin{array}{l}\text { D. 02/12/1993 } \\
\text { D. 26/12/2000 }\end{array}$ \\
\hline Poblado Minero de «Aldea Moret» & Lugar de Interés & D. 27/05/2011 \\
\hline Palacio de Carvajal & Monumento & D. 04/05/2012 \\
\hline La Preciosa Sangre, Casa del Sol, Conventual de San Francisco & I. 05/04/2004 \\
\hline & & \\
\hline
\end{tabular}

Fuente: Dirección General del Patrimonio Cultural. Gobierno de Extremadura.

Por tanto, esta amalgama de recursos y reconocimientos, que ha sido expuesta con anterioridad, se sustenta en un patrimonio que se ubica, principalmente, dentro del perímetro del Conjunto Histórico. Sobre este espacio gravita la mayor parte de las visitas turísticas y, además, no sólo acapara la mayor parte de las actuaciones llevadas a cabo en materia de políticas turísticas, sino que acoge gran número de las actividades culturales que se programan cada año. 
Como consecuencia de lo anterior, los recursos culturales han funcionado como desencadenante de la afluencia de visitantes y la consiguiente aparición de infraestructuras y equipamientos, en respuesta a este nuevo papel asumido por la ciudad, a partir de los inicios de la década de los noventa que ha conllevado importantes transformaciones (reordenación del tráfico, nuevos aparcamientos, remodelación de espacios públicos, adecuación del patrimonio para facilitar visitas turísticas etc.). Además, como es lógico, estos recursos han sido y son la base del material divulgativo y promocional distribuido en ferias y certámenes especializados.

Por otra parte, y acompañando a estos recursos, se ha ido diseñando una agenda cultural en la que se incluyen actividades programadas, con periodicidad fija o esporádica, que gozan de cierta capacidad de atracción turística. Cáceres acoge este tipo de actividades apoyándose en la red de equipamientos complementarios de uso recreativo-cultural y de espacios públicos al aire libre. Estas actividades culturales hay que incardinarlas en las políticas que se han venido acometiendo en las últimas décadas. Bajo el formato de mega-evento, no exento de cierta polémica por conflictos de uso del centro histórico, hay que citar la celebración del festival WOMAD, que en el año 2011 alcanzó su vigésima edición, tras arrancar en 1992. Además, como eventos consolidados y de una extensa trayectoria caben citar el Festival de Teatro Clásico de Cáceres y el Otoño Musical de Cáceres, acompañados por una fértil relación de certámenes de trayectoria más corta (musicales, festivos, expositivos, gastronómicos, teatrales...) que completan la agenda cultural cacereña.

Por último, de singular hay que definir la existencia, dentro del Casco Antiguo de Cáceres, con lo que ello conlleva, de un espacio natural protegido en lo que constituye una rentable simbiosis entre patrimonio y especies silvestres. Se trata de la ZEPA (Zona de Especial Protección de Aves): Colonia de Cernícalo Primilla de la Ciudad Monumental de Cáceres. Esta especie está incluida dentro del Catálogo Regional de Especies Amenazadas de Extremadura y en la categoría de especies sensibles a la alteración de su hábitat (Junta de Extremadura, 2008). El espacio protegido afecta a 15,72 hectáreas donde se concentra una importante población reproductora de cernícalo primilla (Falco naumanni).

\section{EL DESARROLLO DE LA ACTIVIDAD TURÍSTICA}

El urbanismo y la ordenación patrimonial han incidido directamente en la dinámica del sector turístico cacereño desde finales de los ochenta. Hasta ese momento el turismo no era más que un subsector embrionario en la economía cacereña, porque el turismo cultural de base urbana estaba emergiendo en España. En este sentido, la relación causal entre la declaración de diferentes ciudades españolas como Patrimonio Mundial y su posterior impacto de cara al desarrollo turístico a escala local, ha sido puesta de manifiesto en diferentes trabajos (García Hernández, 2007; García y Calle, 2005; Melgosa, 2001; Mondéjar, Jiménez y Gómez, 2009; Troitiño Torralba, 2011; Troitiño Vinuesa, 2002 y 2009; TURESPAÑA, 1996).

\section{III.1. La evolución de la oferta}

La tabla 2 no deja lugar a dudas de que los últimos 25 años han sido claves en el desarrollo de la red de establecimientos hoteleros de la ciudad, en contraste con lo sucedido en décadas previas en la que con datos de Rengifo $(1991,1993)$ se aprecia, rotundamente, el 
lento ritmo de crecimiento. Por tanto, la realidad turística que presenta Cáceres en el año 2010 se sustenta en lo acontecido durante los últimos cinco lustros, conforme a la siguiente propuesta de crecimiento en etapas:

- Etapa inicial que se corresponde con el periodo 1986-1995. Durante estos nueve años se instalan en la ciudad los primeros hoteles de cuatro estrellas, con la apertura de cuatro establecimientos en los años 1990, 1991, 1992 y 1995, utilizando como referencia la proximidad al Casco Antiguo y su inserción dentro de los límites del Conjunto Histórico. Estos son los casos del Parador de Cáceres, que se ubica en la zona intramuros, sobre los palacios de los Marqueses de Torreorgaz del siglo XV y la Casa de Ovando Mogollón, Perero y Paredes (XVI-XVIII), y el actual NH Palacio de Oquendo, gestionado entonces por la cadena Meliá y ubicado extramuros en el palacio del Marqués de Oquendo (XVII). Por el contrario, el Hotel V Centenario se situó en la zona del ensanche, junto a la Nacional 630, y el Hotel Ceres Golf, gestionado por sucesivas empresas desde su apertura en el año 1995, hoy con un futuro incierto, eligió los terrenos del campo de golf a unos 5 kilómetros del centro de la ciudad. Con estas aperturas la ciudad de Cáceres se situó en el mapa del turismo nacional, en un periodo en el que se ultimó la reconversión de la radial N-5 (carretera de Extremadura) en autovía de Extremadura A-5, acortando el tiempo de desplazamiento desde Madrid-Barajas, principal centro emisor de turistas a la ciudad, coincidiendo con la efeméride del V Centenario, en cuyo marco se llevaron a cabo numerosas actividades bajo el paraguas del programa «Extremadura enclave 92».

- Etapa de consolidación: 1996-2005. Este periodo se caracteriza, desde el punto de vista de la oferta, por la culminación de los proyectos iniciados y la gestación de nuevos proyectos que acabarían abriendo al público en la siguiente etapa. De nuevo, son los hoteles de cuatro estrellas los que protagonizan el principal refuerzo de la oferta en este periodo, aunque a un ritmo muy inferior al de la etapa anterior. En este sentido, hay que reseñar que durante el periodo de 25 años estudiado, el quinquenio en el que la oferta creció de un modo más importante coincide con el comprendido entre 1990-1995. Asimismo, el Conjunto Histórico se refuerza como elemento de atracción para la apertura de nuevos hoteles. El hotel AH Ágora Cáceres de cuatro estrellas se instala en un edificio de nueva planta situado en las proximidades de la Plaza Mayor, al igual que el Hotel Las Marinas, de idéntica categoría, y situado junto a la Plaza de San Juan, ambos dentro del Conjunto Histórico. Por su parte, el Extremadura Hotel de cuatro estrellas, el de mayor capacidad de la ciudad, se ubica en la zona del ensanche, a menos de diez minutos a pie del perímetro del Conjunto Histórico, con una oferta de casi 300 plazas.

- Etapa de diversificación que arranca en el año 2006. En este periodo la oferta de la ciudad de Cáceres se diversifica en un triple sentido: en primer lugar, se completa la gama de categorías de hoteles representados en Cáceres con la apertura de dos hoteles de cinco estrellas (uno en el Casco Antiguo intramuros, el Hotel Atrio, y el otro fuera del casco urbano, Hotel Palacio de los Arenales); en segundo lugar, se desarrollan a buen ritmo otras tipologías de alojamientos inexistentes en etapas anteriores, como son los apartamentos turísticos (14 establecimientos con una oferta total de 75 plazas) y, en tercer lugar, se abre en el año 2008 el primero de los hoteles de gran capacidad dentro 
del Conjunto Histórico, el Gran Hotel Don Manuel de cuatro estrellas y 250 plazas. En esta etapa también toman impulso los hoteles de tres estrellas con dos nuevas aperturas dentro del conjunto histórico: Hotel Casa Don Fernando y Hotel Albarragena.

Tabla 2

EVOLUCIÓN DEL NÚMERO ABSOLUTO DE PLAZAS EN ESTABLECIMIENTOS HOTELEROS. CÁCERES. 1986-2010

\begin{tabular}{|l|r|r|r|r|r|}
\hline CATEGORÍA & $\mathbf{1 9 8 6}$ & $\mathbf{1 9 9 5}$ & $\mathbf{2 0 0 5}$ & $\mathbf{2 0 1 0}$ & Saldo 1986-2010 \\
\hline PENSIONES & 39 & 39 & 98 & 51 & $\mathbf{+ 1 2}$ \\
\hline HOSTALES $1^{*}$ Y 2* & 279 & 329 & 406 & 236 & $\mathbf{4 3}$ \\
\hline HOTELES $1^{*}$ & 346 & 303 & 303 & 201 & $\mathbf{- 1 4 5}$ \\
\hline HOTELES 2* & 90 & 90 & 180 & 180 & $\mathbf{+ 9 0}$ \\
\hline HOTELES 3* & 247 & 247 & 120 & 456 & $\mathbf{+ 2 0 9}$ \\
\hline HOTELES 4* & - & 707 & 1.145 & 1.360 & $\mathbf{+ 1 . 3 6 0}$ \\
\hline HOTELES 5* & - & - & - & 112 & $\mathbf{+ 1 1 2}$ \\
\hline TOTAL & 1001 & 1.715 & 2.252 & 2.596 & $\mathbf{+ 1 . 5 9 5}$ \\
& & $(+714)$ & $(+537)$ & $(+344)$ & \\
\hline
\end{tabular}

Fuente: Elaboración propia a partir de datos de la Dirección General de Turismo.

Con todo ello, en los cinco lustros estudiados se aprecia que el crecimiento de la oferta se ha nutrido de las plazas generadas en el arco de los hoteles con categoría de 3 a 5 estrellas, especialmente los de cuatro estrellas. De este modo, si en el año 1986 los hoteles cacereños encuadrados dentro del abanico de 3 a 5 estrellas aportaban al total de plazas el $24,67 \%$, en el año 2010 el peso de las plazas de estos mismos establecimientos se fortaleció considerablemente hasta representar el 74,26\%. Por tanto, es evidente el cambio cualitativo producido. Dentro del grupo de establecimientos hoteleros destaca la primacía de los hoteles de 4 estrellas, que han pasado de no tener presencia en 1986, a tener un peso del 52,38\% en el cómputo total de plazas del año 2010, diferenciándose con claridad del resto de categorías de hoteles, hostales y pensiones. Tras éstos, tan sólo los de tres estrellas disfrutan de cierta entidad, en lo que a número de plazas se refiere, con un porcentaje del 17,5\% en el año 2010. Este comportamiento, referido a un mayor protagonismo de los hoteles de categoría superior, no es exclusivo de Cáceres, ya que es extrapolable al resto del territorio nacional, aunque en medida diferente, donde los hoteles de 3, 4 y 5 estrellas pasan de ofertar en 1999 un total de 635.236 plazas a 1.011.973 en 2010, frente al resto de establecimientos (hoteles de 2 y 1 estrella y hostales) que descienden de las 375.752 plazas en 1999, a las 351.962 en 2009 (INE 1999 y 2009, Encuesta de Ocupación Hotelera).

Finalmente, no se puede obviar que, en relación con el modelo turístico de Cáceres, desarrollado a partir de las actividades y atractivos que oferta el Conjunto Histórico, tanto el espacio intramuros, como las áreas próximas a él, acogen buena parte de los establecimientos de mayor categoría de la ciudad (3, 4 y 5 estrellas), sin que ello comprometa el cálculo de que en la zona del ensanche y periferia se ubiquen los establecimientos de mayor capacidad, levantados sobre edificios de nueva planta, en lugar de aprovechar, en gran medida, edificios históricos, como ocurre dentro del Conjunto Histórico. Y todo ello a pesar de la problemática 
asociada con la accesibilidad en vehículo privado, principal medio de transporte utilizado por los turistas que vienen a Extremadura, y de sus tarifas oficiales, superiores a las de hoteles de igual categoría situados en otras áreas. Del mismo modo, hay que señalar que, además de los hoteles de 3, 4 y 5 estrellas, el Conjunto Histórico acoge establecimientos hoteleros de categoría inferior, tanto hoteles de 1 y 2 estrellas, como hostales y pensiones, tal y como se aprecia en la Figura 1. La renta de situación es evidente. Para terminar este análisis del comportamiento de la oferta de los alojamientos en los últimos 25 años, hay que dejar cons-

Figura 1

UBICACIÓN DE HOTELES Y EQUIPAMIENTOS CULTURALES EN EL PERIODO 1986-2010

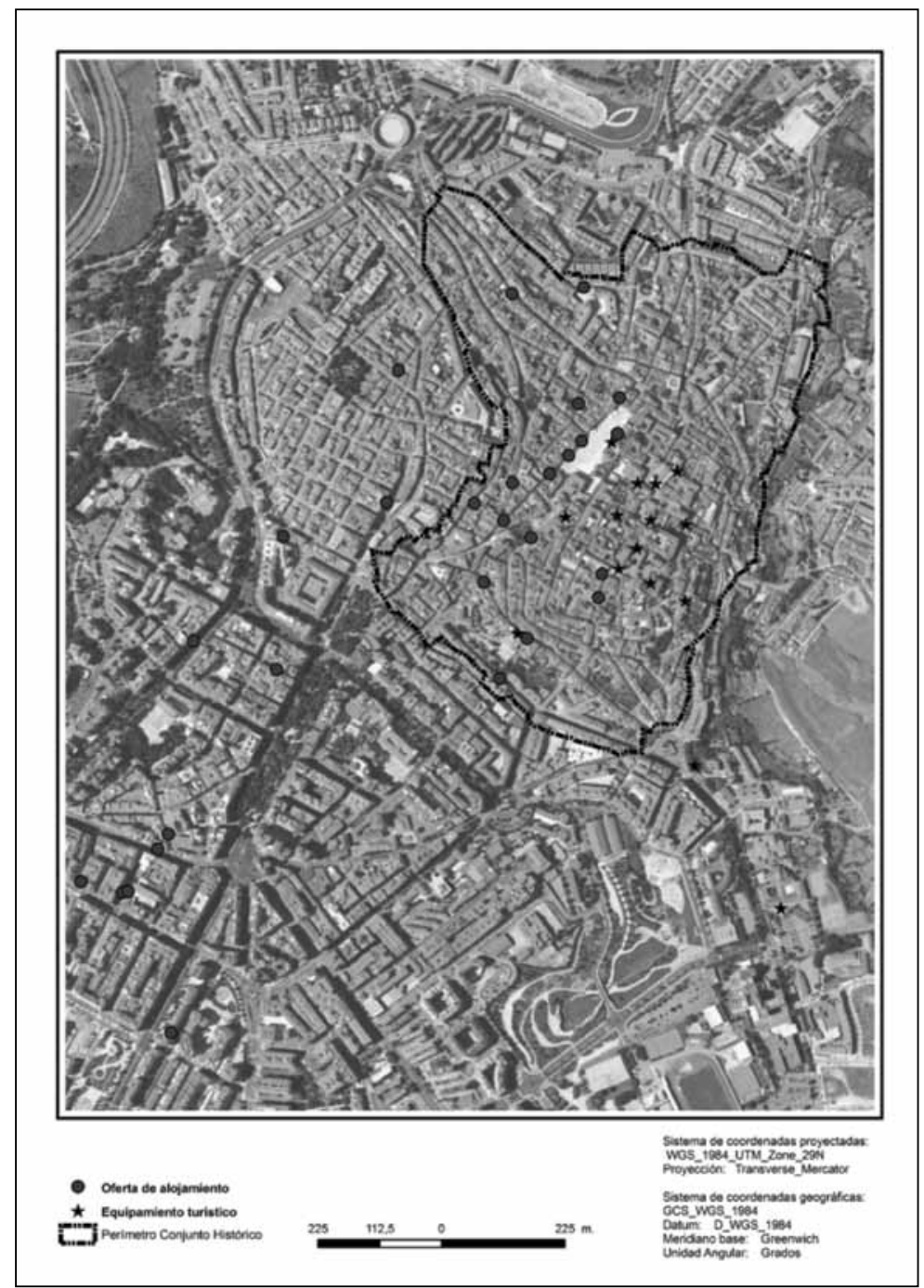


tancia de las tensiones que ha introducido en el sector del turismo de la ciudad de Cáceres, dependiente en exceso de los flujos de los residentes nacionales, la crisis económica, coyuntura que ha conllevado la disminución de plantillas de diversos establecimientos, ajustes de precios, paralización de nuevos proyectos y perspectivas negativas para alguno de los establecimientos abiertos, si no se corrige la situación.

Por último, la oferta alojativa de Cáceres se complementa con un camping y varios albergues turísticos que diversifican, aún más, la disponibilidad y variedad de habitación.

En cuanto al sector de la restauración, aunque siempre cumple el doble papel de ofrecer servicios a la población residente y a los viajeros (turistas y visitantes), lo incorporamos a este análisis turístico por razones obvias. En Cáceres, factores asociados con la ubicación de estos establecimientos, en áreas próximas o alejadas del Conjunto Histórico, determinan un mayor uso, que no exclusivo, por parte de los viajeros. Esta máxima no se cumple siempre, ya que existen otros hechos diferenciales que influyen en el hecho de que la elección del viajero se decante a favor de determinados establecimientos. De cualquier forma, el Conjunto Histórico acoge una amplia relación de restaurantes, especialmente en la Plaza Mayor y aledaños. La red de restaurantes alcanzó la cifra global de 144 locales con una capacidad superior conjunta de 11.500 plazas en la ciudad de Cáceres (Junta de Extremadura, 2010). Dicha red se ha adaptado a las exigencias de unos turistas que buscan menús y productos de calidad de la zona.

Asimismo, han surgido en este periodo nuevos negocios y profesiones que dependen de los turistas en un alto porcentaje: tiendas especializadas en la venta de productos artesanales y gastronómicos de Extremadura, guías profesionales de turismo y, tímidamente, agencias de viajes haciendo las funciones de receptivo local.

\section{III.2. Equipamientos complementarios}

Además de los establecimientos hoteleros y extra-hoteleros la ciudad se ha dotado en las dos últimas décadas de la mayor parte de los equipamientos complementarios que, actualmente, están en funcionamiento. Englobamos bajo la expresión de equipamiento complementario, a todas aquellas instalaciones que son utilizadas por los turistas para satisfacer sus necesidades de ocio. La existencia de estos equipamientos es determinante para el desarrollo de actividades turísticas dentro del entorno urbano, con la consiguiente repercusión desde el punto de vista del incremento de la estancia media en destino, satisfacción del turista y diversificación de sus atractivos. En Cáceres resulta especialmente significativa la dotación de equipamientos ligada al Conjunto Histórico y, en particular, al espacio intramuros, aunque no faltan los que se ubican en otros puntos de la ciudad. En la dotación de este tipo de equipamientos han jugado un papel primordial las administraciones, responsables de la puesta en marcha de la mayor parte de ellos en las dos últimas décadas. En este sentido, resultaron fundamentales las inversiones realizadas en el marco del Plan de Excelencia Turística (2,7 millones de euros, financiados conjuntamente por la administración local, autonómica y nacional) (Rodríguez, 2008), desarrollado en los primeros años de la presente centuria. En consonancia con los ambiciosos objetivos que tenía el Plan (incremento de la calidad de los servicios turísticos, mejora del medio urbano, aumento, diversificación y mejora de la oferta complementaria y puesta en valor de los recursos, entre otros) se pusieron en marcha los primeros centros turísticos que han venido combinando la labor informativa, expositiva y de interacción con 
el patrimonio, cuya utilidad ha quedado avalada por el número de visitantes que reciben cada año, tal y como se expondrá en el próximo epígrafe. El Plan ejecutó intervenciones de gran calado para el visitante: trabajos en el aparcamiento y área estancial de Valhondo, adecuación de centros de atención (Torre de los Pozos, Torre de Bujaco, Cáceres Galarza), colocación de paneles panorámicos, iluminación de la Plaza Mayor y mobiliario urbano.

Además de los centros gestionados por el Ayuntamiento existen otros de gran relevancia, adscritos a la administración regional y a entidades de carácter privado, que complementan, de igual modo, la oferta. Dentro de ellos se encuentran museos, centros de interpretación, fundaciones y espacios expositivos, como se relacionan en la Tabla 3.

Tabla 3

PRINCIPALES EQUIPAMIENTOS COMPLEMENTARIOS DE ÍNDOLE TURÍSTICO-CULTURAL DE LA CIUDAD DE CÁCERES. AÑO 2011

\begin{tabular}{|c|c|}
\hline \multicolumn{2}{|c|}{ DENTRO DEL CONJUNTO HISTÓRICO } \\
\hline $\begin{array}{c}\text { Centro de Artes Visuales } \\
\text { Fundación Helga de Alvear }\end{array}$ & Museo de Cáceres \\
\hline Fundación Mercedes Calles-Carlos Ballestero & Museo de la Concatedral \\
\hline Centro de Artesanía del Palacio de los Moraga & Centro Turístico Baluarte de los Pozos \\
\hline Casa Museo Árabe & Patronato de Turismo y Artesanía \\
\hline Museo Municipal Ciudad de Cáceres & Museo de Armas \\
\hline Centro de Divulgación de la Semana Santa & Centro de Interpretación de las Tres Culturas de \\
\hline \multicolumn{2}{|c|}{ FU Torre de Bujaco } \\
\hline $\begin{array}{c}\text { Centro de Interpretación del Campamento } \\
\text { romano de Cáceres el Viejo }\end{array}$ & $\begin{array}{c}\text { Centro de Interpretación de la Minería en } \\
\text { Extremadura (Aldea Moret) }\end{array}$ \\
\hline $\begin{array}{c}\text { Centro de Interpretación de la Cueva de } \\
\text { Maltravieso }\end{array}$ & Museo de Historia y Cultura Casa Pedrilla \\
\hline
\end{tabular}

Fuente: Elaboración propia.

No menos importantes son, dentro de la oferta complementaria, los puntos de información turística de la administración regional y municipal, ubicados dentro del Conjunto Histórico. Además de las oficinas de turismo, adscritas al Ayuntamiento y a la Comunidad Autónoma, algunos de los equipamientos anteriores prestan esa labor, al menos de forma parcial. De igual modo, un edificio clave para la actividad cultural de Cáceres es el Gran Teatro donde se desarrollan de forma permanente actividades de índole cultural. Finalmente, consignamos la existencia de otros equipamientos complementarios de uso turístico, como las instalaciones de la Institución Cultural el Brocense (instalaciones veteranas de la década de los ochenta) y el Palacio de Congresos, recientemente inaugurado en el 2011, que están íntimamente ligados a la potencialidad de Cáceres en materia de turismo de reuniones. En esta línea viene trabajando el Convention Bureau, nacido de la cooperación surgida entre el Ayuntamiento y los empresarios. 
Figura 2

DISTRIBUCIÓN DE PLAZAS HOTELERAS Y EQUIPAMIENTOS CULTURALES EN EL CONJUNTO HISTÓRICO

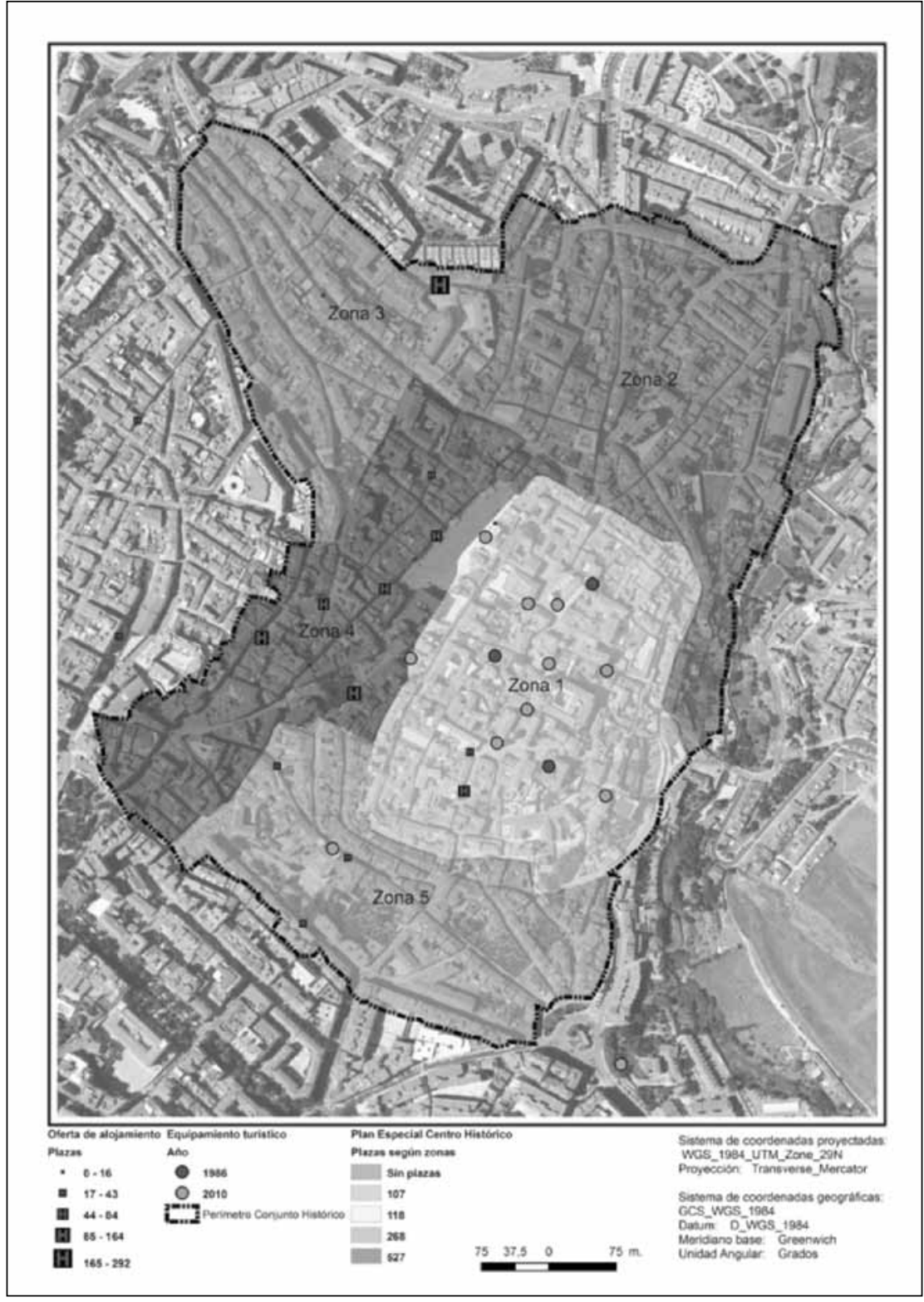

Acompañando a la oferta, y gracias al proyecto NETUR, se han acometido acciones que están relacionadas con la gestión, en lo que es un segundo paso de cara a una mayor integración de Cáceres en el mercado turístico. Entre otros contenidos, en el proyecto NETUR 
se han planteado medidas como la creación de una central de información permanente de eventos, la integración en la estructura de un observatorio turístico permanente, la creación del sistema integral Cáceres Card o de una central de reservas.

Por otra parte, y con carácter innovador se ha desarrollado, recientemente, la instalación de códigos QR en 82 puntos de interés turístico de la ciudad, mediante los que se puede obtener información con la ayuda del teléfono móvil, aspecto que cobra especial relevancia si consideramos que se ofrece acceso gratuito a Internet mediante cobertura Wi-Fi.

\section{EL COMPORTAMIENTO DE LOS FLUJOS TURÍSTICOS}

El fortalecimiento de la oferta no tendría sentido sin la consolidación de unos flujos turísticos que, en términos de demanda, se pueden desglosar entre turistas y excursionistas. La principal consecuencia derivada de la presencia de turistas es el volumen de pernoctaciones, con el consiguiente reflejo en los niveles de ocupación de los establecimientos hoteleros y extra-hoteleros. Lamentablemente, la ausencia de datos sobre la demanda en la ciudad de Cáceres ha sido una triste realidad hasta que el INE pasó a considerarla como punto turístico desagregado en sus encuestas en el año 2003. Por este motivo, y por la ausencia de entes públicos o privados que hayan asumido esa tarea a escala municipal en épocas pretéritas, es imposible realizar una retrospectiva tan amplia como en el caso de la oferta. Por ello, seleccionamos una serie de variables relacionadas con el grado de ocupación y la demanda, elaboradas por el INE que ayuden a comprender la realidad actual:

- Grado de ocupación por plazas en establecimientos hoteleros. En el último quinquenio, coincidente con la etapa de diversificación (2006-2010), el grado de ocupación de los establecimientos hoteleros ha disminuido del 45,99\% del año 2006 al 41,30\% del año 2010, comportamiento que se debe explicar por dos motivos: el contexto de crisis nacional y el continuo crecimiento de la oferta. Este grado de ocupación, no obstante, es superior al registrado a nivel provincial. A modo de ejemplo se puede señalar que, durante el año 2010, el grado de ocupación de la ciudad de Cáceres estuvo más de diez puntos por encima del registrado a nivel provincial. En cuanto a la ocupación de los establecimientos hoteleros durante el ciclo anual, se aprecia que los meses de abril, agosto y septiembre, muestran los picos más elevados de ocupación, frente a los meses de invierno. Durante el año 2010, último de referencia, la cresta más elevada de ocupación se registró, al igual que ocurrió en los años 2009, 2007, 2006 y 2003, en el mes de abril. El examen del calendario de estos años nos indica que la Semana Santa coincidió en abril (en el año 2010 entre marzo y abril). Por su parte, en los años 2004 (Semana Santa en abril) y 2005 (Semana Santa en marzo) el mes con mayor ocupación fue septiembre y, en 2008 (Semana Santa en marzo) y agosto. Por su parte, las ocupaciones más bajas se registraron durante los meses de noviembre, diciembre, enero y febrero. Durante el año 2010 la diferencia de ocupación entre abril (56.41\%) y enero $(24,84 \%)$, fue de un $32 \%$. Este ritmo estacional se observa, igualmente, si tenemos en cuenta la ocupación durante los fines de semana, aunque, en este caso, los porcentajes de ocupación media suben considerablemente en todos los años referenciados. En el 2010 la diferencia de ocupación entre abril $(79,84 \%)$ y diciembre 
$(25,66 \%)$ alcanzó el 54,00\%. Con ello se confirma la fortaleza del turismo de fin de semana, en consonancia con factores ligados al tipo de turismo dominante (nacional) y a la ostensible mejora de las infraestructuras terrestres (carreteras), que permiten la llegada de turistas de núcleos de población de gran peso demográfico, en un tiempo inferior a las tres horas, como son los casos de Madrid o Sevilla.

- Número de viajeros en establecimientos hoteleros. En los últimos años el número de viajeros en los establecimientos muestra un evidente declive. De los 226.977 viajeros registrados en 2006 se pasa a los 215.490 de 2010, lo que supone una pérdida de viajeros en esta tipología de establecimientos que es la que predomina en la ciudad. De igual modo, las pernoctaciones experimentan un retroceso, al pasar de 372.324 en el año 2006 a las 341.574 pernoctaciones del año 2010. El reparto de los turistas a lo largo de los doce meses mostró altibajos que no se corresponden de forma exacta con los mayores niveles de ocupación, debido a que el número de pernoctaciones por turista varió de unos meses a otros. La tendencia muestra que durante el verano el número de turistas fue mayor, aunque su repercusión, traducida en número de pernoctaciones, fue menor. Sin duda, esto obedece a que en verano nos encontramos ante un turismo de tránsito más acusado, posiblemente, hacia otros destinos situados en el litoral. Por ello, el número de pernoctaciones por turista varió en el año 2010 de las 1,41 y 1,47 pernoctaciones/turista de los meses de julio y agosto, respectivamente, a las 1,82 del mes de abril que, en cualquier caso, son cortas.

- Procedencia de viajeros en establecimientos hoteleros. La procedencia de los viajeros alojados en hoteles refleja la predominancia de los turistas residentes frente a los extranjeros, de acuerdo con la dinámica que se manifiesta en Extremadura y en la mayor parte de las zonas de interior de España. Durante el año 2010, el 10,54\% de los viajeros alojados eran residentes en el extranjero, responsables del 10,14\% de las pernoctaciones. Su procedencia fue mayoritariamente europea (Unión Europea) y, en particular, de países fronterizos con España (Portugal y Francia), a los que habría que añadir los clásicos emisores europeos hacia España, como son Alemania y el Reino Unido. Con estos datos, hay que señalar sin ningún género de dudas la alta dependencia de los flujos turísticos que llegan a Cáceres de la demanda interna.

Figura 3

VOLUMEN DE PERNOCTACIONES Y VIAJEROS EN CÁCERES, SEGÚN LUGAR DE RESIDENCIA. AÑO 2010

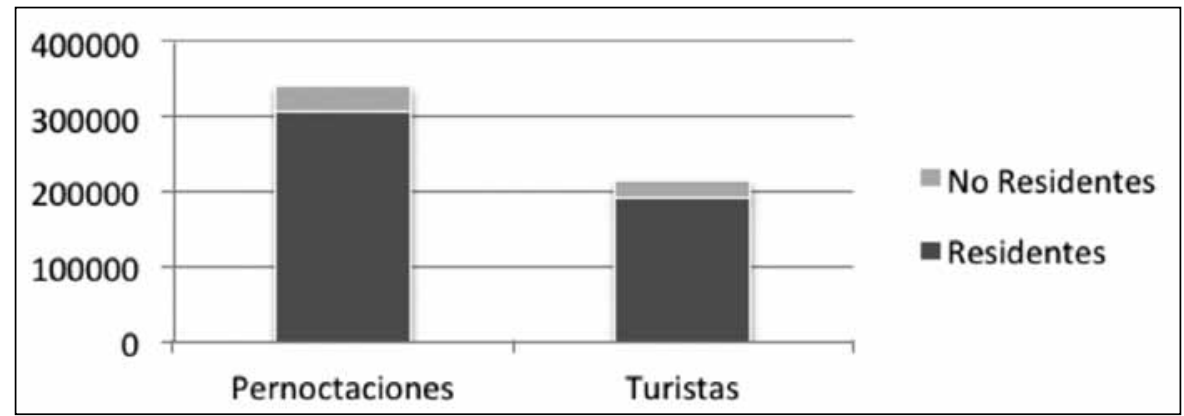

Fuente: Elaboración propia a partir de datos del INE. 
Al margen de los datos del INE, hemos rastreado la posible existencia de otras fuentes que nos proporcionaran una mayor información relacionada con la demanda, dirigiéndonos a entidades de carácter local (Ayuntamiento), regional (Gobierno de Extremadura) y privado. En concreto se han obtenido datos de visitantes del Museo de Cáceres, Diputación, Fundaciones privadas, oficinas de turismo y otros centros. Estos datos, que adquieren una dimensión diferente, porque engloban turistas y visitantes, permiten extraer conclusiones de gran calado que muestran, sobre todo, el interés de los turistas por la oferta complementaria. Para corroborarlo hemos seleccionado los datos obtenidos del Museo de Cáceres, oficina de turismo del Gobierno de Extremadura y centros dependientes del Ayuntamiento de Cáceres. En todos los ejemplos se observan las abultadas cifras de visitantes que reciben este tipo de sedes y la existencia de un patrón muy parecido a la hora de analizar la procedencia y su ritmo estacional:

a) Museo de Cáceres. El Museo de Cáceres está situado en uno de los puntos neurálgicos del Casco Antiguo, la Plaza de San Mateo. En este museo, además de la exposición permanente, con sus secciones de Arqueología, Etnografía y Bellas Artes, se programan algunas actividades complementarias de índole cultural. A estos elementos se une la singularidad de alojar dentro de su recinto el aljibe almohade, lo que contribuye a realzar su atractivo turístico. En la última década el museo ha venido recibiendo, en los tres años tomados como muestra, cifras similares de visitantes: 158.970 en el año 2000, 157.605 en el año 2005 y 156.826 en 2010. Estas cifras globales se han distribuido de forma parecida a lo largo de los doce meses del año, en los tres años seleccionados a título de ejemplo. Se observa una pauta que hace de la primavera el periodo más demandado, junto con los meses estivales de agosto y septiembre, además de octubre. En el otro lado de la balanza se situarían los meses de invierno, especialmente enero.

Tabla 4

NÚMERO DE VISITANTES DEL MUSEO DE CÁCERES (AÑOS 2000, 2005 Y 2010)

\begin{tabular}{|l|l|l|l|l|l|l|l|l|l|l|l|}
\hline \multicolumn{10}{|c|}{ AÑO 2000 } \\
\hline ENE & FEB & MAR & ABR & MAY & JUN & JUL & AGO & SEP & OCT & NOV & DIC \\
\hline 4230 & 7825 & 9987 & 21006 & 12269 & 9684 & 11280 & 22813 & 14387 & 19113 & 11544 & 14832 \\
\hline \multicolumn{10}{|c|}{ ANO 2005 } \\
\hline ENE & FEB & MAR & ABR & MAY & JUN & JUL & AGO & SEP & OCT & NOV & DIC \\
\hline 5648 & 9323 & 22296 & 19106 & 16343 & 9238 & 8475 & 17925 & 13554 & 13193 & 10236 & 12268 \\
\hline \multicolumn{10}{|c|}{ AÑO 2010 } \\
\hline ENE & FEB & MAR & ABR & MAY & JUN & JUL & AGO & SEP & OCT & NOV & DIC \\
\hline 7420 & 10477 & 18041 & 24454 & 16376 & 9486 & 8512 & 15098 & 12939 & 15803 & 9612 & 8608 \\
\hline $\begin{array}{l}\text { En estas cifras de visitantes están incluidos los del Centro de Interpretación de la Cueva de } \\
\text { Maltravieso, que es una Sección del Museo de Cáceres. }\end{array}$ \\
\hline
\end{tabular}

Fuente: Dirección General del Patrimonio Cultural. Junta de Extremadura. 
b) Centros de Información dependientes del Ayuntamiento. El Ayuntamiento de Cáceres cuenta con una nutrida red de centros de información turística y espacios de carácter expositivo, ubicados, mayoritariamente, dentro del recinto del Casco Antiguo y su entorno más inmediato. Esta red adquiere entidad a partir de la ejecución del Plan de Excelencia Turística que se consuma, principalmente, dentro del primer quinquenio del siglo XXI. La nutrida red de centros de información y espacios expositivos constituye uno de los pilares más sólidos de la oferta complementaria de Cáceres. Está integrada por los siguientes centros: Oficina de Información Turística municipal, Oficina de Guías Turísticos, Centro Turístico Cáceres Galarza, Centro de Divulgación de la Semana Santa, Centro Turístico Baluarte de los Pozos, Centro de Interpretación de las Tres Culturas de la Torre de Bujaco y Palacio de la Isla. La interacción de estos centros con el turismo es evidente, constituyendo una valiosa fuente de información sobre el número de visitantes desde el año 2003, fecha en que la Sección de Turismo del Ayuntamiento de Cáceres comienza a recopilar información sobre el número de visitantes de forma desagregada, en cuanto a estacionalidad y procedencia se refiere. Las cifras, expuestas en la Tabla 5, evidencian un elevado uso de estos centros, prueba indudable de la importancia que tiene en el turismo la oferta complementaria. La información recogida de forma conjunta ${ }^{1}$ en la red de centros de adscripción municipal, alcanza desde sus inicios dígitos de seis cifras, especialmente durante la segunda parte del decenio del presente siglo, a medida que el número de centros de información se ha visto incrementado. Esta circunstancia debe ser tenida en cuenta para hacer una adecuada lectura de los datos.

Tabla 5

NÚMERO DE VISITANTES EN CENTROS DE INFORMACIÓN DEPENDIENTES DEL AYUNTAMIENTO DE CÁCERES. AÑOS 2003-2010

\begin{tabular}{|l|c|c|c|}
\hline AÑO & RESIDENTES & NO RESIDENTES & TOTAL \\
\hline 2003 & 137.701 & 21.723 & 159.424 \\
\hline 2004 & 124.936 & 17.595 & 142.531 \\
\hline 2005 & 130.093 & 15.393 & 145.486 \\
\hline 2006 & 371.992 & 39.541 & 411.373 \\
\hline 2007 & 371.992 & 117.586 & 489.508 \\
\hline 2008 & 408.531 & 50.029 & 458.560 \\
\hline 2009 & 604.776 & 55.892 & 660.668 \\
\hline 2010 & 556.663 & 56.562 & 613.225 \\
\hline
\end{tabular}

Fuente: Sección de Turismo. Ayuntamiento de Cáceres.

1 Debe tenerse en cuenta, para una correcta lectura de los datos, que las cifras globales hacen referencia al número de visitantes recogidos en un número de centros que ha ido variando cada año, debido a la sucesiva apertura de nuevos espacios de información. A título de ejemplo, los visitantes registrados durante el año 2006 se recogieron en 5 centros, los del 2007 y 2008 en 6, los del 2009 en 8 y los del 2010 en 7. 
Además de la información numérica por meses y procedencia, la Sección de Turismo del Ayuntamiento ha esbozado un perfil del turista que visita Cáceres, a partir de un cuestionario distribuido en el Centro de Interpretación de la Torre de Bujaco, Centro Cáceres-Galarza y Oficina de Información Turística municipal, llegando a definir los rasgos siguientes:

- Edad. Por grupos de edad los turistas se reparten de la siguiente forma: 40-60 años $(42,44 \%), 20-40$ años $(40,30 \%)$, menores de 20 años $(14,25 \%)$ y mayores de 60 años $(3,28 \%)$.

- Forma de organización. El 89,82\% viaja con familiares y amigos, seguido a gran distancia por el $8,77 \%$, que llega en grupos organizados y un 1,41\%, que vienen solos.

- Motivaciones. Algo más de la mitad se sienten traídos por el arte y la historia $(52,50 \%)$, seguido de los que declararon su interés por conocer y degustar la gastronomía $(28,13 \%)$ y, un último grupo, por la naturaleza, observación de aves, leyendas, etc. $(19,38 \%)$.

- Fuente de Información. Los turistas se informaron, principalmente, a través de amigos y familiares $(46,49 \%)$, internet $(30,97 \%)$, guías de turismo y libros $(18,71 \%)$, oficinas de turismo $(3,81 \%)$ y prensa $(1,06 \%)$.

c) Oficina de Turismo del Gobierno de Extremadura. La oficina de turismo de Cáceres es un centro de información que dispone de series estadísticas más largas. Mostramos las importantes cifras que se recogen desde el año 1998 hasta el 2009, en las que se observa, una tendencia a la baja, tanto de residentes como de no residentes.

Tabla 6

VISITANTES REGISTRADOS EN LA OFICINA DE TURISMO DE CÁCERES, ADSCRITA AL GOBIERNO AUTONÓMICO. AÑOS 1998-2009

\begin{tabular}{|c|c|c|c|}
\hline AÑO & RESIDENTES & NO RESIDENTES & TOTAL \\
\hline 1998 & 208.632 & 31.536 & 240.168 \\
\hline 2000 & 224.412 & 34.320 & 258.732 \\
\hline 2005 & 328.864 & 37.150 & 366.014 \\
\hline 2009 & 203.064 & 27.076 & 230.140 \\
\hline
\end{tabular}

Fuente: Dirección General de Turismo. Junta de Extremadura.

Con respecto a la procedencia geográfica de estos flujos hay una clara conexión, en su estructura, con la que presentan los viajeros alojados: mayoría de residentes frente a no residentes. El esqueleto de procedencias de los viajeros recogidos en este centro nos sitúa en la órbita de dos mercados:

- Intrarregional: contingente formado por, aproximadamente, un tercio del total de los visitantes residentes. Es, sin duda, una porción significativa del total.

- Suprarregional: colectivo de viajeros que integra los dos tercios restantes de viajeros residentes, dentro de los cuales destaca la Comunidad de Madrid, seguida de 
la de Andalucía. La suma de los viajeros de estas comunidades viene a significar, en la serie estadística de los años 2004-2010, entre un 25 y un 30\%. Tras estas dos comunidades autónomas es recurrente, en los años objeto de estudio, la aparición de otras regiones con porcentajes que rondan el 5\%. En este grupo estarían incluidas comunidades limítrofes, como Castilla y León, y distantes en términos de separación kilométrica, como Cataluña, Valencia, Castilla León y País Vasco. El resto de comunidades tiene un carácter menos representativo con porcentajes que se mueven en cifras inferiores al 4\%. La importancia de los mercados nacionales en los lugares de interés cultural también se ha puesto de manifiesto en estudios de alcance europeo, como los llevados a cabo por Richards (2001a, 2001b). En cuanto a los no residentes, su conformación denota una composición lógica en cuanto a proximidad geográfica, que explicaría la primacía del mercado portugués y, en menor medida, francés. Junto a estas dos nacionalidades destacan, dentro de Europa, alemanes e ingleses y, fuera de ella, los turistas llegados desde los Estados Unidos.

\section{CONCLUSIONES}

De la investigación realizada se infiere que el desarrollo turístico de Cáceres se ha nutrido de los avances experimentados en los cinco lustros transcurridos desde la declaración de Cáceres como Patrimonio Mundial. En el año 1986 la declaración de la UNESCO se sumó a los reconocimientos previos de Conjunto Histórico y Tercer Conjunto Monumental de Europa, contribuyendo a ensalzar un rico patrimonio histórico que estaba lejos de su integración en el mercado turístico, pese a su buen estado de conservación, diversidad (villa medieval, renacentista, barroca e ilustrada) y especificidad (la primacía del conjunto sobre los elementos singulares).

La gestión del patrimonio cacereño ha sido paradigmática entre 1986 y 2010, periodo en el que diferentes inmuebles históricos fueron rehabilitados para usos públicos de diferente contenido: alojamientos, espacios expositivos y de reuniones, museos y dependencias de la administración local, provincial y autonómica, dibujando un nuevo panorama en el Conjunto Histórico.

La rehabilitación de las viejas arquitecturas patrimoniales con declaración de BIC ha permitido su protección y refuncionalización para dar cobijo a nuevos equipamientos: culturales (Casa de los Caballos / Museo de Arte Contemporáneo -1990-; Casa Fortaleza y solar de los Espadero / Archivo Histórico Provincial -1996-; Casa de los Becerra / Fundación Mercedes Calles y Carlos Ballestero -2006-; Casa Grande /Fundación Helga de Alvear -2010-); universitarios (Casa de los Ovando-Mogollón / Servicios Centrales de la UEX -2003-; CasaPalacio de los Duques de Abrantes / Residencia Femenina Cristo Rey -1992-), y turísticos (Palacios de los Marqueses de Torreorgaz y Casa de los Ovando, Mogollón, Perero y Paredes / Parador Nacional de Turismo -1989-; Palacio de los Ovando / Hotel NH Palacio Oquendo -1991-, y Casa de la Fundación Valhondo / Hotel Casa Don Fernando -2008- y la discutida intervención del Hotel Atrio Relais \& Châteaux -2007/2011-).

La aspiración de Cáceres a Capital Europea de la Cultura 2016 generó unas justas expectativas en 2010 que se tradujeron en el Proyecto Estratégico: «Cáceres 2016: De Intramuros a Europa», mediante una candidatura que definió el modelo urbano-patrimonial 
de Cáceres como «Ciudad Mediterránea de Urbanismo Cultural: Del Conocimiento a la Innovación, a través de la Creatividad». Dicho Plan, que pretendía reforzar el papel de Cáceres como destino turístico del Patrimonio Mundial pretendía desarrollarse mediante los siguientes instrumentos: Plan Director de Intervención del Centro Histórico (Plaza Mayor y entornos); Plan de Recualificación Ambiental de Plazas (San Juan y La Concepción) y Espacios Públicos; Plan de Revitalización Funcional de Locales y Terrazas; Plan Integral de Tráfico, Aparcamientos y Peatonalización; Plan Director de la Ribera del Marco, y Plan Director del Poblado Minero de Aldea Moret. Para la gestión se constituyó el Consorcio Cáceres 2016, liderado por la alcaldesa de Cáceres con financiación pública-privada. Por desgracia, el fallo del jurado -más político que técnico- dejó fuera de concurso a las ciudades de Córdoba y Cáceres, indiscutiblemente, las de más solventes contenidos culturales y patrimoniales.

En el periodo de estudio se produjo un crecimiento paulatino de la oferta turística, manifestado no sólo en el incremento del número de establecimientos y plazas hoteleras, conforme a un patrón que tuvo en cuenta la proximidad a la zona intramuros del Conjunto Histórico, en consonancia con su incuestionable capacidad de atracción turística, sino en la dotación de nuevos equipamientos de índole cultural, ubicados mayoritariamente dentro del espacio murado. Este crecimiento de los establecimientos hoteleros se puede compartimentar en tres etapas, en las que se observa una secuencia que va cubriendo, en primer lugar, los aspectos básicos, para posteriormente evolucionar hacia la consolidación y, finalmente, hacia la diversificación.

Con estos cambios se propició un ambiente favorable para que el número de turistas en establecimientos hoteleros superara la barrera de los 200.000, aunque se aprecia un retroceso que hay que relacionar con la situación de crisis económica y la dependencia del turismo interno. El análisis de la ocupación hotelera nos confirma la fortaleza del turismo de corta estancia, vinculado principalmente a los fines de semana, en armonía con el tipo de consumidor mayoritario (nacional) y la accesibilidad predominante (terrestre por carretera).

En suma, el constatado crecimiento turístico de Cáceres ha tenido una serie de efectos directos y colaterales que han aportado beneficios a la ciudad en el ámbito económico (inversiones y empleo), cultural (incremento de actividades), rehabilitador (inversiones en el patrimonio) y de imagen al exterior con un gran recorrido aún que se debe caminar en los próximos años.

En el horizonte mediato de 2020, Cáceres debe consolidar su condición de destino turístico-cultural del Patrimonio Mundial, para lo cual precisará resolver los estrangulamientos de su posición periférica con la llegada del AVE Madrid-Lisboa y proceder a la comercialización conjunta de productos turísticos que ensamblen congresos, eventos y patrimonio histórico-artístico con oferta complementaria de rutas turísticas de naturaleza, ornitología, gastronomía y sol y playa de interior.

\section{REFERENCIAS}

ALCÓN OLIVERA, G. et al. (1991): Cáceres. Plan General de Ordenación Urbana. Avance. Cáceres, Servicio de Urbanismo del Ayuntamiento. Oficina Técnica de Revisión del PGOU. 
CAJA ESPAÑA (2011): Datos Económicos y Sociales de las Unidades territoriales de España, 15 de octubre de 2011. Disponible en http://internotes.cajaespana.es

CAMPESINO FERNÁNDEZ, A.J. (1982): Estructura y paisaje urbano de Cáceres. Madrid. Colegio de arquitectos de Extremadura, $375 \mathrm{pp}$.

CAMPESINO FERNÁNDEZ, A.J. (Coord.). (1999): Comercio, Turismo y Cambios Funcionales en las Ciudades Españolas, Patrimonio de la Humanidad. Cáceres, Cámara Oficial de Comercio e Industria de Cáceres, 284 pp.

CAMPESINO FERNÁNDEZ, A.J. (2004): «La revitalización patrimonial con fines turístico-culturales», en PARDELLAS DE BLAS, X.X. (Dir.). Potencial turístico de territorios periféricos. Vigo, Servizo de Publicacions de la Universidade de Vigo, 51-75.

DELTA SUR, S.L. (1987): Plan Especial de Protección y Revitalización del Patrimonio Arquitectónico de la Ciudad de Cáceres. Cáceres, Ayuntamiento (III vols., fotos y planos). (Arquitecto Director, Santiago Rodríguez Gimeno).

GARCÍA HERNÁNDEZ, M. (2007): «Entidades de planificación y gestión turística a escala local. El caso de las Ciudades Patrimonio de la Humanidad de España». Cuadernos de Turismo, 20. Murcia, Universidad de Murcia, 79-102.

GARCÍA, M. y CALLE, M. de la. (2005): «Nuevas estrategias para la renovación del producto turístico urbano. El caso de las ciudades Patrimonio de la Humanidad». VIII Forum Internacional sobre las Ciencias, las Técnicas, y el Arte aplicadas al Marketing. Madrid, Universidad Complutense, Facultad de Ciencias Económicas y Empresariales, 386-414.

GUERRERO SÁNCHEZ, M. (1991): «Espacios urbanos sin uso. Las viviendas vacías en el centro histórico cacereño (1990)», XII Congreso Nacional de Geografía, Sociedad y Territorio, Valencia, Asociación de Geógrafos Españoles y Universidad de Valencia, $509-515$.

INE (1999-2010): Encuesta de ocupación hotelera. Disponible en www.ine.es

INE (2006-2010): Encuesta de ocupación en apartamentos turísticos. Disponible en www. ine.es

JUNTA DE EXTREMADURA (2008): Catálogo regional de especies amenazadas de Extremadura. Fauna II/ Clase Aves. Montijo. Consejería de Industria, Energía y Medio Ambiente.

LOZANO BARTOLOZZI, M.M. (1980): El desarrollo urbanístico de Cáceres (siglos XVI$X I X)$. Cáceres, Servicio de Publicaciones de la Universidad de Extremadura, 325 pp.

MARTÍNEZ DE PISÓN STAMPA, E. (1976): Segovia. Evolución de un paisaje urbano. Madrid, Colegio de Ingenieros de Caminos, Canales y Puertos, 436 pp.

MELGOSA ARCOS, F.J. (2001): «Turismo y sostenibilidad en las Ciudades Patrimonio de la Humanidad. Principios, marco e instrumentos de actuación», en AA. VV. Ciudades Patrimonio de la Humanidad de España. Urbanismo y Patrimonio Histórico. Madrid, Ministerio de Cultura / Grupo de Ciudades Patrimonio de la Humanidad de España, 197-220.

MONDÉJAR, F., JIMÉNEZ, J.A. y GÓMEZ, M.A. (Eds.). (2009): Turismo cultural en ciudades Patrimonio de la Humanidad. Cuenca, Universidad de Castilla y La Mancha.

PIZARRO GÓMEZ, F.J. (2002): Cáceres. Paisajes Urbanos de Extremadura. (1) Cáceres, CICON, Ediciones, 162 pp.

RICHARDS, G. (2001a): ¿Nuevos caminos para el turismo cultural? Barcelona. Diputación de Barcelona. Disponible en http://www.diba.es/ 
RICHARDS, G. (2001b): «El desarrollo del turismo cultural en Europa». Estudios Turísti$\cos , 50,3-13$.

RENGIFO GALLEGO, J. I. (1991): Turismo y oferta hotelera en la provincia de Cáceres. Cáceres. Cámara de Comercio e Industria de Cáceres.

RENGIFO GALLEGO J. I. (1993): El turismo en Extremadura. Cáceres. Junta de Extremadura.

RENGIFO GALLEGO, J.I. (2011): «Evaluación del papel del turismo en la ciudad de Cáceres, como factor de cambio, en el periodo 1990-2010», en XVI Congreso de AECIT, Málaga.

RODRÍGUEZ CANCHO, M. (2008): «Cáceres. Los retos de su oferta turística: excelencia y calidad en destino», en TROITIÑNO, M. A., García, J. S. y GARCÍA, M. (Coords.) Destinos turísticos: viejos problemas, ¿nuevas soluciones? Ediciones de la Universidad de Castilla la Mancha, Cuenca, 311-322.

TORRES, L. y TERRASSE, H. (s.f.): Ciudades hispanomusulmanas. Volumen 1. Madrid, Ministerio de Asuntos Exteriores, Instituto Hispano-Árabe de Cultura.

TROITIÑO TORRALBA, L. (2011): «Ciudades Patrimonio de la Humanidad de España: Dinámica Turística en Tiempos de Crisis (2000-2009)». En XII Coloquio del Grupo de Turismo, Ocio y Recreación, Espacios y Destinos Turísticos en Tiempos de Globalización y Crisis. Vol. 1. Madrid, AGE, Grupo TERAP, 131-148.

TROITIÑO VINUESA, M.Á. (2002): «Ciudades Patrimonio de la Humanidad: Desafíos de Interpretación, Planificación y Gestión Turística», en BLANQUER CRIADO, D. (Dir.). Ordenación y Gestión del Territorio Turístico. Valencia, Fundació Universitat Jaime I Empresa, 351-405.

TROITIÑO VINUESA, M.Á. (Ed.). (2009): Ciudades Patrimonio de la Humanidad: Patrimonio, Turismo y Recuperación Urbana. Sevilla, Universidad Internacional de Andalucía-Junta de Andalucía, 276 pp.

TROTIÑO VINUESA M.Á. y TROITIÑO TORRALBA, L. (2009) Turismo y patrimonio en Castilla y León: las ciudades Patrimonio de la Humanidad (Ávila, Salamanca y Segovia) como destinos turísticos de referencia, Polígonos, Revista de Geografía, 19, 145-178.

TURESPAÑA. (1996): Estudio sobre turismo y desarrollo sostenible en las ciudades históricas con patrimonio arquitectónico y monumental. Madrid, Secretaría de Estado de Turismo. (Equipo técnico: TROITIÑO VINUESA, M. Á. (Dir.); BRANDIS GARCÍA, D.; DEL RÍO LAFUENTE, I.; GUTIÉRREZ PUEBLA, J.; MARTÍN GIL, F. COLABORADORES: ALONSO GARCÍA, M.; DE LA CALLE VAQUERO; GARCÍA HERNÁNDEZ; LOBO MONTERO, P.).

UNESCO (1986): Old Town of Cáceres, Province of Cáceres, State Party, Spain. World Heritage List, File name 384. Decision of The World Heritage Committee General Conference, Paris, 26/11/1986. 
